\title{
Vicarious breathlessness: an inferential perceptual learned transposition process that may not be inconsequential to either patient or caregiver
}

\author{
Miriam J. Johnson ${ }^{1}$ and David Gozal ${ }^{2}$ \\ Affiliations: ${ }^{1}$ Wolfson Palliative Care Research Centre, Hull York Medical School, University of Hull, Hull, UK. \\ ${ }^{2}$ Sections of Pediatric Sleep Medicine and Pulmonology, Dept of Paediatrics, Biological Sciences Division, \\ Pritzker School of Medicine, The University of Chicago, Chicago, IL, USA.
}

Correspondence: David Gozal, Section of Pediatric Sleep Medicine, Dept of Pediatrics, Pritzker School of Medicine, Biological Sciences Division, The University of Chicago, KCBD, Room 4100, 900 E. 57th Street, Mailbox 4, Chicago, IL, 60637, USA. E-mail: dgozalduchicago.edu

@ERSpublications

Education and training for caregivers of breathless patients is crucially important http://ow.ly/U52C30iTCpW

Cite this article as: Johnson MJ, Gozal D. Vicarious breathlessness: an inferential perceptual learned transposition process that may not be inconsequential to either patient or caregiver. Eur Respir J 2018; 51: 1800306 [https://doi.org/10.1183/13993003.00306-2018].

People with common chronic cardiorespiratory conditions can live with chronic breathlessness for years [1]. Disabling chronic breathlessness, persisting despite optimum treatment of the underlying cause [2], is experienced by almost all patients with advanced lung disease, such as chronic obstructive pulmonary disease (COPD) [3], and carries a significant emotional, social, health and economic load. Intimately related to physical activity, chronic breathlessness reduces the ability to carry out activities of daily living [4] and restricts the role in the family, workplace or wider society [5]. These consequences, with additional frightening severe episodes of breathless crises, lead not only to acute emotional responses that not only widely activate a multitude of brain regions [6], but also promote the insidious development of depression, anxiety and panic, and a reduction in physical and mental quality of life proportionate with the severity of breathlessness [7].

Inevitably, the responsibility to support daily physical and psychological needs falls to life partners or family members, very few of whom anticipated such a situation at the outset of the relationship, and none of whom volunteered to be destined into a family with such a challenge. Family and friends make up a large workforce who provide care for people with chronic conditions around the world (an estimated 6.5 million in the UK [8] and 65 million in the USA [9]), and include the $7-10 \%$ of the population who have given hands-on personal care for someone at the end of life in the previous 5 years [10, 11]. The number of people providing informal care for someone with chronic breathlessness is less well delineated, but $66-77 \%$ of people with advanced lung cancer [12], COPD [13, 14], neuromuscular disease [15] or cystic fibrosis [16] reportedly have a family caregiver. This often unrecognised and relatively unsupported community manages complex medication and oxygen regimens, with vigilance (often at night) for breathlessness crisis which is frightening for both patient and caregiver. This caregiver role often brings detriment to their own social/work life balance, as well as to physical and mental health, and is usually provided with no or suboptimal training. Consequently, many caregivers may have poor confidence, be 
overprotective [17], drive increased emergency health service use [18, 19] and may frustrate the patient [20]. A systematic review and synthesis of 101 qualitative studies of patient, caregiver and clinician experience of chronic breathlessness described the complex interplay between the patient's and caregiver's coping and help-seeking behaviours around breathlessness, and the clinician's attention to breathlessness, as well as to treatment of the disease [5]. One of the prominent conclusions from this review was that engaged coping strategies and appropriate help-seeking practices allowed maximum "breathing space" for the patient.

But what about the caregiver? The important information provided in this issue by Herzog et al. [21] begins to address this issue. If caregivers witnessing severe breathlessness also experience vicarious breathlessness, then this phenomenon may add fuel to a desire to restrict exertion (with accompanying deleterious patient deconditioning) or to facilitate unnecessary calling of emergency services for a self-limiting breathlessness crisis.

The process through which the transfer of perceptual breathlessness from the patient to the caregiver occurs is unclear. To a certain extent, there needs to be a priori familiarity with the concept of breathlessness, something that is naturally acquired from very early in life through physical activity, particularly during peaks of anaerobic activity that characterise child play [22]. However, such familiarity and learned perception do not necessarily foster the concurrent emotional empathy response to the visual observation of a patient manifesting symptoms and signs of breathlessness. The latter is clearly an additional learned process, which is further strengthened through the assumption of the caregiver role. The concurrent association of learned breathlessness awareness and learned emotional response to the latter is likely the basis for the inferential perceptual transposition that Herzog et al. [21] report in their study. To better understand the potential ramifications of this phenomenon, it is important to address, if only very briefly, the cognitive processes that prescribe the emergence of vicarious breathlessness. Contemporary theory in the field of cognitive neuroscience readily discriminates among the processes and utilities that serve to categorise sensory experiences, i.e. the existence of both explicit and implicit systems of category learning. These highly divergent systems will progressively acquire category rules by active hypothesis testing or adaptive behaviours by association and reinforcement, respectively [23, 24]. In a setting of visually perceived stimuli such as breathlessness, the implicit system will learn using multidimensional processes that integrate across stimulus features, and this process will depend on associative-learning pathways to link breathlessness in the patient to adaptive responses by the caregiver (e.g. discontinue physical activity or provide a treatment intervention to patient even if not always required). Thus, implicit learning produces category knowledge that is opaque to declarative consciousness, a process that could hamper conscious judgement in decision-informed approaches, unless the process of vicarious breathlessness is modulated by specific and concurrent formal training using explicit learning paradigms.

Education and training for caregivers is therefore crucially important. Although clinicians endorse the need for joint patient/caregiver training to help with confidence and self-efficacy, implementation of this desirable goal is usually provided in an ad hoc manner only during clinic appointments [25]. FARQUHAR et al. [26] identified six key caregiver-reported areas for education: 1) understanding breathlessness; 2) managing anxiety, panic and breathlessness; 3) managing infections; 4) keeping active; 5) living positively; and 6) knowing what to expect in the future. Many of these areas are very relevant if the caregiver is also experiencing breathlessness. In the study by Herzog et al. [21], the participants were students or healthy volunteers, many were women, and many of their previous experiences with respiratory conditions, including their familiarity with breathlessness, were not specifically sought. It would therefore be interesting to see how findings would compare if participants were caregivers of patients with respiratory disorders with either no experience or varying degrees of previous exposures to breathlessness crises. The other factor to consider is that many caregivers may have morbidity of their own with personal experience of chronic breathlessness. Central perception of breathlessness in people living with chronic breathlessness involves the pre-frontal associative cortex (fear and memory) in addition to multiple other central pathways previously delineated in healthy subjects [27, 28]. If both patient and caregiver have COPD, then vicarious breathlessness might contribute to an increasing spiral of breathlessness in both, a process that could be further amplified by their intrinsic and vicarious antecedent memories of frightening breathlessness. Thus, improved understanding of the conglomerate of interdependencies and mechanisms underlying chronic and acute breathlessness in the patient and its vicarious counterparts in the caregiver will be critically important for the patient, the caregiver and the clinical team, and form part of the "thinking" approach to management in the recently proposed "breathing, thinking, functioning" model of respiratory disease management [29]. 


\section{References}

1 Bausewein C, Booth S, Gysels M, et al. Understanding breathlessness: cross-sectional comparison of symptom burden and palliative care needs in chronic obstructive pulmonary disease and cancer. J Palliat Med 2010; 13: 1109-1118.

2 Johnson MJ, Yorke J, Hansen-Flaschen J, et al. Towards an expert consensus to delineate a clinical syndrome of chronic breathlessness. Eur Respir J 2017; 49: 1602277.

3 Moens K, Higginson IJ, Harding R. Are there differences in the prevalence of palliative care-related problems in people living with advanced cancer and eight non-cancer conditions? A systematic review. J Pain Symptom Manage 2014; 48: 660-677.

4 Smith AK, Currow DC, Abernethy AP, et al. Prevalence and outcomes of breathlessness in older adults: a national population study. J Am Geriatr Soc 2016; 64: 2035-2041.

5 Hutchinson A, Barclay-Klingle N, Galvin K, et al. Living with breathlessness: a systematic literature review and qualitative synthesis. Eur Respir J 2018; 51: 1701477.

6 Gozal D, Omidvar O, Kirlew KA, et al. Identification of human brain regions underlying responses to resistive inspiratory loading with functional magnetic resonance imaging. Proc Natl Acad Sci USA 1995; 92: 6607-6611.

7 Currow DC, Dal GE, Ferreira D, et al. Chronic breathlessness associated with poorer physical and mental health-related quality of life (SF-12) across all adult age groups. Thorax 2017; 72: 1151-1153.

8 Office for National Statistics. 2011 Census. www.ons.gov.uk/census/2011census Date last accessed: February 4, 2018.

9 Caregiver Action Network. Caregiver statistics: Statistics on Family Caregivers and Family Caregiving. http:// caregiveraction.org/resources/caregiver-statistics Date last accessed: February 10, 2018.

10 Currow DC, Burns C, Agar M, et al. Palliative caregivers who would not take on the caring role again. J Pain Symptom Manage 2011; 41: 661-672.

11 Johnson MJ, Allgar V, Macleod U, et al. Family caregivers who would be unwilling to provide care at the end of life again: findings from the Health Survey for England population survey. PLoS One 2016; 11: e0146960.

12 Farquhar MC, Prevost A, McCrone P, et al. Is a specialist breathlessness service more effective and cost-effective for patients with advanced cancer and their carers than standard care? Findings of a mixed-method randomised controlled trial. BMC Med 2014; 12: 194.

13 Farquhar MC, Prevost AT, McCrone P, et al. The clinical and cost effectiveness of a Breathlessness Intervention Service for patients with advanced non-malignant disease and their informal carers: mixed findings of a mixed method randomised controlled trial. Trials 2016; 17: 185

14 Gautun H, Werner A, Luras H. Care challenges for informal caregivers of chronically ill lung patients: results from a questionnaire survey. Scand J Public Health 2012; 40: 18-24.

15 Magliano L, Politano L. Family context in muscular dystrophies: psychosocial aspects and social integration. Acta Myol 2016; 35: 96-99.

16 McGuffie K, Sellers DE, Sawicki GS, et al. Self-reported involvement of family members in the care of adults with CF. J Cyst Fibros 2008; 7: 95-101.

17 Gabriel R, Figueiredo D, Jacome C, et al. Day-to-day living with severe chronic obstructive pulmonary disease: towards a family-based approach to the illness impacts. Psychol Health 2014; 29: 967-983.

18 Hutchinson A, Pickering A, Williams P, et al. Breathlessness and presentation to the emergency department: a survey and clinical record review. BMC Pulm Med 2017; 17: 53.

19 Wakabayashi R, Motegi T, Yamada K, et al. Presence of in-home caregiver and health outcomes of older adults with chronic obstructive pulmonary disease. J Am Geriatr Soc 2011; 59: 44-49.

20 Snippe E, Maters GA, Wempe JB, et al. Discrepancies between patients' and partners' perceptions of unsupportive behavior in chronic obstructive pulmonary disease. J Fam Psychol 2012; 26: 464-469.

21 Herzog M, Sucec J, Van Diest I, et al. Observing dyspnoea in others elicits dyspnoea, negative affect and brain responses. Eur Respir J 2018; 51: 1702682.

22 Berman N, Bailey R, Barstow TJ, et al. Spectral and bout detection analysis of physical activity patterns in healthy, prepubertal boys and girls. Am J Hum Biol 1998; 10: 289-297.

23 Nomura EM, Maddox WT, Filoteo JV, et al. Neural correlates of rule-based and information-integration visual category learning. Cereb Cortex 2007; 17: 37-43.

24 Smith JD, Beran MJ, Crossley MJ, et al. Implicit and explicit category learning by macaques (Macaca mulatta) and humans (Homo sapiens). J Exp Psychol Anim Behav Process 2010; 36: 54-65.

25 Ewing G, Penfold C, Benson JA, et al. Clinicians' views of educational interventions for carers of patients with breathlessness due to advanced disease: findings from an online survey. J Pain Symptom Manage 2017; 53: 265-271.

26 Farquhar M, Penfold C, Benson J, et al. Six key topics informal carers of patients with breathlessness in advanced disease want to learn about and why: MRC phase I study to inform an educational intervention. PLoS One 2017; 12: e0177081.

27 Gozal D, Hathout GM, Kirlew KA, et al. Localization of putative neural respiratory regions in the human by functional magnetic resonance imaging. J Appl Physiol (1985) 1994; 76: 2076-2083.

28 Herigstad M, Hayen A, Evans E, et al. Dyspnea-related cues engage the prefrontal cortex: evidence from functional brain imaging in COPD. Chest 2015; 148: 953-961.

29 Spathis A, Booth S, Moffat C, et al. The Breathing, Thinking, Functioning clinical model: a proposal to facilitate evidence-based breathlessness management in chronic respiratory disease. NPJ Prim Care Respir Med 2017; $27: 27$. 